\title{
The Performance Evaluation of Multilevel Fuzzy Comprehensive Model of College Seminar Based on Student Perspective in China
}

\author{
Hongmin Liu ${ }^{1 . a}$ Yandong Yang ${ }^{2 . b}$ and Yichao Han ${ }^{3 . c, ~ *}$ \\ ${ }^{1,3}$ School of Economics and Management, Zhejiang University of Science and Technology, \\ Hangzhou 310023, China; \\ ${ }^{2}$ School of Politics and Public Administration, Zhejiang University of Technology, Hangzhou \\ 310023, China



Keywords: Seminars; Performance evaluation; Fuzzy judgment

\begin{abstract}
College seminars are based on student development-oriented teaching. The paper bases on the students' perspective and constructs the index system of the performance evaluation of the college seminar. It includes the effectiveness of learning environment of the construction and the teaching process and the academic evaluation feedback, the main achievement of the students, the overall satisfaction of the students five first-level indicators and 19 secondary indicators related to them. There is a multilevel fuzzy comprehensive evaluation model based on AHP and FCE model.
\end{abstract}

\section{Introduction}

The seminar has become an important teaching method in the research universities of developed countries in Europe, the United States and Japan. After the middle of the 20th century, the freshman seminar has officially listed the new curriculum as part of the undergraduate curriculum system in Harvard University ${ }^{[1]}$. $75 \%$ of the courses are 15 people for a class of seminars in Yale University ${ }^{[2]}$. Owing to the limit from the expansion of college enrollment and tight teaching resources, the construction and implementation of Chinese college seminar started late, and the current stage of the teaching organization is still the main class. Tsinghua University for the first time in China to open new students' seminar in 2003, after more than a decade, a number of research universities have launched a seminar to explore establishing plans and teaching methods. The teaching seminars include the basic characteristics of the study and discussion, however, the traditional way of teaching students in the evaluation of content, evaluation criteria, evaluation functions and other aspects do not meet the small class, students as the main part. It is of great significance to construct a student-oriented scientific and rational teaching performance evaluation index system based on student's perspective and student-centered learning situation, which is of great significance to the promotion and sustainable development of the teaching quality.

\section{The construction of the evaluation index system for seminar}

The college seminar focuses on the creative thinking and comprehensive ability of the developing students. Teachers are the organizers and the guide of the course study, but not the lecturer. The student is the subject of classroom learning, rather than the passive knowledge receiver. Therefore, the evaluation of teaching performance of seminars must be based on learning, from the perspective of learning to describe, such as the effectiveness of learning environment to create and the study process and academic evaluation feedback, and the main assessment of students and other evaluation indicators, as well as the real implementation of learning to teach.

The effectiveness of the learning environment.

Peking University starts the reform pilot of undergraduate small class seminar teaching in the fall of 2012, the survey shows that part of the courses still exist some aspects of the problem including classroom hardware and class methods ${ }^{[6]}$. The most prominent feature of the seminar is interactive, participatory, and teaching as the main part, so we should create a good teacher and student 
communication atmosphere ${ }^{[7]}$. The construction of the learning environment of seminars is an important part of the traditional teaching methods. Its teaching situs, mentor, methods and timetables are the key indicators.

The teaching venue of the seminars of the dedicated classroom should be arranged in special room with activities tables and chairs, and the student development counseling room. It should avoid the use of traditional lectures. Experts recommend that the type of classroom in colleges should be clearly divided into lectures and seminars classrooms at least ${ }^{[8]}$. The seminar requires academic teachers own higher capability and experiences, and the current domestic and foreign research colleges to open the adaptive new courses and academic seminars generally led by the academic professor. It can suit for the need of the seminar and interaction between teachers and students, the seminar class time from 1.5 to 2 hours, about two-thirds the course is scheduled for about 1.5 hours. How to arrange a reasonable time is a focus on the issue in the course.

The effectiveness of the teaching process.

The obvious difference between the seminar and the traditional teaching is that the purpose of teaching is not to grasp the quantity of knowledge, but teaching design of the problem-oriented, through the teacher's inspiration and lead to let the students learn finding the problem, exploring the problem, querying problem, developing students from a professional perspective to analyze the problem, learning to find out a path tool of the solution. Therefore, the effectiveness of the seminar course is a key evaluation index of the performance of the university seminar, which is the core of the oriented problem and solving problem. It requires the teacher from the path of proposing the problem, analyzing and solve the process to achieve ${ }^{[9]}$.

The effectiveness of academic evaluation feedback.

The seminar focus on the process of evaluation rather than the results of the evaluation, and the feedback mechanism of academic evaluation according to the teaching characteristics of the seminar, and comprehensive playing the academic evaluation of the diagnosis, guidance and incentive function, from the following four key evaluation indicators to reflect:

The feedback channel of the main body of multiple evaluations. The comprehensive evaluation scheme of teacher evaluation, self evaluation and mutual evaluation will changes the situation of teachers as the subject of single evaluation. It can introduce the students, relevant social practice units, project review experts and other diversified subjects into the academic evaluation system of the seminar. ${ }^{[10]}$

The multi-dimensional academic evaluation system. According to the different dimensions of the re-optimization of the combination, a multi-faceted mirror of the evaluation index system should be built. It can both evaluate the students master the mirror of knowledge, and the mirror of the evaluate students' attitudes and methods of learning, participation of curriculum and other aspects , but It be able to evaluate students to find, analyze, solve the problem of the mirror, so that students of different development orientation with the individual needs of the effective feedback can map their own horizontal state in this polygon prism evaluation system.

The process of evaluation of the timely feedback. The academic evaluation of the seminar should establish the guidance of the light process of the heavy process, designing the multistage process evaluation in the course and giving the students feedback the evaluation results to play the reasonable role timely, so that it work correction and encouragement.

The modified plans of feedback guidance. One of the important purposes of the semester review is to enable students to clarify their future direction. An effective learning improvement plan must be based on two elements, one is fully discussed based on the teachers and students themselves own development, so that the teachers and students reached a consensus and cooperation spirit. Another is designing a series of mending plan that based on pre-evaluation of feedback.

\section{The main achievements of the seminar students.}

The seminar focuses on cultivating students' adaptability and academic research ability as well as innovative thinking ability, Its ultimate effect of students needs their own perception. The core elements mainly relates to professional cognitive identity, and the improve promote of thinking and 
learning methods and the intensified ability of the team collaborative ability, and the several aspects of directly interaction with the professor:

The professional awareness and identity.

As far as freshman is concerned, it is very important to recognize the professional cognition. Through the form of seminar, it is helpful to solve the problem of academic and learning adaptability of freshmen in the first grade, so that the students' awareness is further strengthened, and It can enhance the identity of the school and professional identity. Academic symposium can further deep the professional identity, stimulating the intrinsic motivation to learn.

The enhancement of thinking and learning methods. The seminar is a very important significance to stimulate students' interest in innovation and awareness, reversing the students' inertia thinking ${ }^{[11]}$, the study of classroom teaching through the design of open participation in the problem, the ability of students analyzing the problem, expanding students divergent thinking ,closing communication between teachers and students, dialogue, interaction, and conducive first-year college students from the secondary school of thinking and learning methods to enhance, the university stage of scientific thinking, innovative thinking and self-learning.

The enhancement of teamwork ability and communication ability. During the course of teaching, the teacher instructs the students to set up the learning group and through the group-oriented teaching in the form of group division and team cooperation, and assigning the research task so that the group guides the team members to realize the division of labor, self-management and cooperation task. This model virtually enhances the student's ability of communicate and enhances the student's teamwork and organizational management skills.

The direct interaction with the professor. Students have the opportunity to directly interact with professors or well-known scholars, feeling the master's academic style, access academic influence and so on.

Through the study of the seminar, the student can gain much knowledge, for example, the survey found that a considerable part of the students to deep the understanding of the students as the main harvest in the new study class, there are some students talking about after class preparation and speaking at the lecture class to obtain a sense of accomplishment.

The overall satisfaction of students.

It should be given by the students to a general evaluation of the degree of satisfaction. The effect of degree of attention and recognition of the students and expected effect in the seminar should be included.

\section{The construction of multilevel fuzzy comprehensive evaluation model for seminar}

The evaluation of teaching performance is a typical multilevel, multi-dimensional, multiple factor evaluation problem, many of which are difficult to measure directly with a specific value, and It only is expressed by the state or degree level, and the evaluation index has a strong mistiness. This evaluation problem can be a better solution by using multilevel fuzzy synthesis method.

The first, the evaluation factor set $U=\left\{u_{1}, u_{2}, \ldots, u_{i}\right\}$ is constructed, that is index set. Where $u_{i}$ is the fact or considered, $\mathrm{i}=1,2, \ldots, \mathrm{n}$.

The second, the comment set $\mathrm{V}=\left\{\mathrm{v}_{1}, \mathrm{v}_{2}, \ldots, \mathrm{v}_{\mathrm{j}}\right\}$ is established, where $\mathrm{v}_{\mathrm{j}}$ represents the evaluation result, $\mathrm{j}=1,2, \ldots, \mathrm{m}$. Such as the comment set $\mathrm{V}=$ \{very good, better, generally, poor, very poor $\}$, that is collection of evaluation level.

The third, the weight set $A=\left(a_{1}, a_{2}, \ldots, a_{n}\right)$ is determined, where an denotes the weight given by the factor $\mathrm{u}_{\mathrm{i}}$, and the weight is determined by the AHP method.

The forth, the fuzzy comprehensive evaluation matrix $R$ is determined. The vector $R\left(u_{i}\right)=\left(r_{i 1}\right.$, $\left.r_{i}, \ldots, r_{i m}\right)$ of the fuzzy mapping $R$ from $U$ to $V$ is called a single factor evaluation, which is a fuzzy subset on V. $r_{i j}\left(0 \leq r_{i j} \leq 1, i=1,2, \ldots, n ; j=1,2, \ldots, m\right)$ represents the membership that the thing can be rated $v_{j}$ from the factor $u_{i}$. The fuzzy mapping of the whole vector is arranged to obtain a comprehensive evaluation of the transformation matrix $R=\left(r_{i j}\right)$. 


$$
\mathrm{R}=\left[\begin{array}{llll}
r_{11} & r_{12} & \ldots & r_{1 m} \\
r_{21} & r_{22} & \ldots & r_{2 m} \\
\ldots & & \ldots & \\
r_{n 1} & r_{n 2} & \ldots & r_{n m}
\end{array}\right]
$$

The fifth, the fuzzy comprehensive evaluation model is establishment. When the weight distribution $\mathrm{A}$ and the transformation matrix $\mathrm{R}$ are known, and the model $\mathrm{B}$ of the fuzzy comprehensive evaluation can be established.

$$
\mathrm{B}=\left(\mathrm{b}_{1}, \mathrm{~b}_{2}, \ldots, \mathrm{b}_{\mathrm{m}}\right)=\left(\mathrm{a}_{1}, \mathrm{a}_{2}, \ldots, \mathrm{a}_{\mathrm{n}}\right) \cdot\left[\begin{array}{llll}
r_{11} & r_{12} & \ldots & r_{1 m} \\
r_{21} & r_{22} & \ldots & r_{2 m} \\
\ldots & & \ldots & \\
r_{n 1} & r_{n 2} & \ldots & r_{n m}
\end{array}\right]
$$

Where $b_{j}=\bigvee\left(a_{i} \wedge r_{i j}\right), 0 \leq b_{j} \leq 1, j=1,2, \ldots, m$.

Through the hierarchical division of the factor, the above model can be extended to a multi-layer fuzzy comprehensive evaluation model. The evaluation result of the next layer is the input of the upper layer evaluation until the top layer.

\section{The practical application of evaluation model}

The seminar of the innovation management course of ZUST as an example, this fuzzy comprehensive evaluation model is used to evaluate the performance of the students. The steps as follows:

As shown in Table 1, the evaluation index system is used to give the performance evaluation factor set (index set) of the seminar, which is divided into two-level index system.

to determine the comment set $\mathrm{V}=\left\{\mathrm{v}_{1}, \mathrm{v}_{2}, \ldots, \mathrm{v}_{\mathrm{m}}\right\}=\{\mathrm{A}+, \mathrm{A}, \mathrm{A}, \mathrm{B}+, \mathrm{B}, \mathrm{B}-, \mathrm{C}\}$, here reviews the number of $\mathrm{m}=7$, with $\mathrm{A}+, \mathrm{A}, \mathrm{A}, \mathrm{B}+, \mathrm{B}, \mathrm{B}-, \mathrm{C}$, respectively, said "very satisfied, satisfied, more satisfied, generally, less satisfied, not satisfied, very dissatisfied" seven evaluation level.

To obtain the evaluation data, determine the index weight and transformation matrix $R=\left(r_{i j}\right)$.

To determine the fuzzy comprehensive evaluation results. Taking into account the space constraints, the middle of the model calculation is omitted, and only the final results are given:

$$
\begin{aligned}
& B=\left(\begin{array}{lllll}
0.20 & 0.25 & 0.20 & 0.25 & 0.10
\end{array}\right)\left[\begin{array}{lllllll}
0.159 & 0.201 & 0.224 & 0.149 & 0.109 & 0.092 & 0.066 \\
0.162 & 0.165 & 0.221 & 0.156 & 0.126 & 0.101 & 0.069 \\
0.157 & 0.157 & 0.235 & 0.142 & 0.139 & 0.104 & 0.066 \\
0.149 & 0.173 & 0.259 & 0.147 & 0.134 & 0.079 & 0.059 \\
0.141 & 0.153 & 0.243 & 0.140 & 0.135 & 0.110 & 0.078
\end{array}\right] \\
& =\left(\begin{array}{lllllll}
0.155 & 0.171 & 0.236 & 0.148 & 0.129 & 0.095 & 0.066
\end{array}\right)
\end{aligned}
$$

It can be seen from the calculation results that the membership degree of the final fuzzy comprehensive evaluation is "0.236", which belongs to A-, which indicates that the teaching performance of the seminar is more appropriate and the calculation result is basically consistent with the actual situation of the seminar. 
Table 1 Student-oriented university seminar performance fuzzy judgment data

\begin{tabular}{|c|c|c|c|c|c|c|c|c|c|c|}
\hline $\begin{array}{c}\text { One class } \\
\text { index }\end{array}$ & Weight & $\begin{array}{l}\text { two class } \\
\text { index }\end{array}$ & Weight & A+ & $\mathbf{A}$ & A- & B+ & B & B- & C \\
\hline \multirow{4}{*}{$\begin{array}{l}\text { The } \\
\text { validity of } \\
\text { learning } \\
\text { environme } \\
\text { nt creation } \\
\quad\left(U_{1}\right)\end{array}$} & \multirow{4}{*}{0.20} & \multirow{4}{*}{$\begin{array}{l}\text { site }\left(\mathrm{U}_{11}\right) \\
\text { teachers } \\
\quad\left(\mathrm{U}_{12}\right) \\
\text { ways }\left(\mathrm{U}_{13}\right) \\
\text { time } \\
\text { arrangement } \\
\quad\left(\mathrm{U}_{14}\right)\end{array}$} & 0.20 & 0.154 & 0.233 & 0.223 & 0.126 & 0.093 & $\begin{array}{c}0.10 \\
4\end{array}$ & 0.067 \\
\hline & & & 0.40 & 0.175 & 0.182 & 0.212 & 0.153 & 0.124 & $\begin{array}{c}0.09 \\
1\end{array}$ & 0.063 \\
\hline & & & 0.30 & 0.143 & 0.221 & 0.231 & 0.159 & 0.094 & $\begin{array}{c}0.08 \\
6\end{array}$ & 0.066 \\
\hline & & & 0.10 & 0.149 & 0.146 & 0.250 & 0.153 & 0.129 & $\begin{array}{c}0.09 \\
3\end{array}$ & 0.080 \\
\hline \multirow{5}{*}{$\begin{array}{l}\text { The } \\
\text { effectivene } \\
\text { ss of } \\
\text { teaching } \\
\text { process } \\
\left(\mathrm{U}_{2}\right)\end{array}$} & \multirow{5}{*}{0.25} & \multirow{5}{*}{$\begin{array}{c}\text { Ask a } \\
\text { question } \\
\left(\mathrm{U}_{21}\right) \\
\text { Solve the } \\
\text { problem } \\
\left(\mathrm{U}_{22}\right) \\
\text { Resolved } \\
\text { organizationa } \\
1 \text { form }\left(\mathrm{U}_{23}\right) \\
\text { Resolve } \\
\text { Resources } \\
\left(\mathrm{U}_{24}\right) \\
\text { Proper } \\
\text { feedback } \\
\left(\mathrm{U}_{25}\right)\end{array}$} & 0.25 & 0.152 & 0.141 & 0.211 & 0.174 & 0.125 & $\begin{array}{c}0.12 \\
3 \\
\end{array}$ & 0.074 \\
\hline & & & 0.25 & 0.154 & 0.165 & 0.221 & 0.161 & 0.093 & $\begin{array}{c}0.11 \\
3 \\
\end{array}$ & 0.093 \\
\hline & & & 0.20 & 0.173 & 0.206 & 0.216 & 0.141 & 0.161 & $\begin{array}{c}0.05 \\
0\end{array}$ & 0.053 \\
\hline & & & 0.15 & 0.176 & 0.133 & 0.226 & 0.146 & 0.134 & $\begin{array}{c}0.13 \\
0 \\
\end{array}$ & 0.055 \\
\hline & & & 0.15 & 0.160 & 0.182 & 0.241 & 0.144 & 0.130 & $\begin{array}{c}0.08 \\
5\end{array}$ & 0.058 \\
\hline \multirow{4}{*}{$\begin{array}{l}\text { The } \\
\text { effectivene } \\
\text { ss of } \\
\text { academic } \\
\text { evaluation } \\
\text { feedback } \\
\left(\mathrm{U}_{3}\right)\end{array}$} & \multirow{4}{*}{0.20} & \multirow{4}{*}{$\begin{array}{c}\text { Feedback } \\
\text { channel }\left(\mathrm{U}_{31}\right) \\
\text { Evaluation } \\
\text { System }\left(\mathrm{U}_{32}\right) \\
\text { Timely } \\
\text { feedback }\left(\mathrm{U}_{33}\right. \\
\text { Improvement } \\
\text { Plan }\left(\mathrm{U}_{34}\right) \\
\end{array}$} & 0.30 & 0.145 & 0.163 & 0.231 & 0.130 & 0.148 & $\begin{array}{c}0.10 \\
2 \\
\end{array}$ & 0.081 \\
\hline & & & 0.25 & 0.169 & 0.164 & 0.256 & 0.146 & 0.106 & $\begin{array}{c}0.11 \\
1 \\
\end{array}$ & 0.048 \\
\hline & & & 0.15 & 0.145 & 0.159 & 0.197 & 0.160 & 0.140 & $\begin{array}{c}0.12 \\
1\end{array}$ & 0.078 \\
\hline & & & 0.30 & 0.165 & 0.145 & 0.240 & 0.140 & 0.158 & $\begin{array}{c}0.09 \\
3\end{array}$ & 0.059 \\
\hline \multirow{5}{*}{$\begin{array}{l}\text { The main } \\
\text { harvest of } \\
\text { the course } \\
\text { students } \\
\left(\mathrm{U}_{4}\right)\end{array}$} & \multirow{5}{*}{0.25} & \multirow{5}{*}{$\begin{array}{c}\text { Identity }\left(\mathrm{U}_{41}\right) \\
\text { Ascending } \\
\left(\mathrm{U}_{42}\right) \\
\text { Collaborative } \\
\text { enhancement } \\
\left(\mathrm{U}_{43}\right) \\
\text { Interactive } \\
\left(\mathrm{U}_{44}\right) \\
\text { A sense of } \\
\text { accomplishm } \\
\text { ent }\left(\mathrm{U}_{45}\right)\end{array}$} & 0.30 & 0.159 & 0.147 & 0.254 & 0.143 & 0.123 & $\begin{array}{c}0.07 \\
6 \\
\end{array}$ & 0.098 \\
\hline & & & 0.25 & 0.142 & 0.160 & 0.254 & 0.135 & 0.146 & $\begin{array}{c}0.10 \\
7\end{array}$ & 0.056 \\
\hline & & & 0.20 & 0.132 & 0.224 & 0.256 & 0.163 & 0.145 & $\begin{array}{c}0.03 \\
8\end{array}$ & 0.042 \\
\hline & & & 0.15 & 0.159 & 0.187 & 0.284 & 0.169 & 0.121 & $\begin{array}{c}0.06 \\
6 \\
\end{array}$ & 0.014 \\
\hline & & & 0.10 & 0.151 & 0.159 & 0.260 & 0.124 & 0.137 & $\begin{array}{c}0.12 \\
0\end{array}$ & 0.049 \\
\hline $\begin{array}{l}\text { The overall } \\
\text { satisfaction } \\
\left(\mathrm{U}_{5}\right)\end{array}$ & 0.10 & $\begin{array}{c}\text { Student's } \\
\text { overall } \\
\text { satisfaction } \\
\left(\mathrm{U}_{51}\right)\end{array}$ & 1.00 & 0.141 & 0.153 & 0.243 & 0.140 & 0.135 & $\begin{array}{c}0.11 \\
0\end{array}$ & 0.078 \\
\hline
\end{tabular}

\section{Conclusions}

Based on the students' perspective, the effectiveness of the learning environment, the effectiveness of the study process, the effectiveness of the academic evaluation feedback, the main achievement of the students, the overall satisfaction of the students play a key role in the teaching performance of the seminar. And qualitative combination of FCE model can be a better study of university teaching 
performance evaluation.

Seminar is still a new form in China s university. On the depth of reform, the re-construction of the evaluation method of the implementation of the seminar means that a "process reengineering" of the traditional teaching evaluation mode, from the perspective of implementation, and the seminar is recommended as follows: First of all, the discussion of the teaching organization in the course, and it is recommended to arrange a seminar to facilitate the classroom discussion and to strengthen the teaching guidance of teachers. Secondly, the higher teachers are the key to the seminar, and it is recommended that the academic departments in the teacher selection, training, incentives and other aspects to strengthen the organization so that ensure the teaching effectiveness and sustainability of the seminar. Finally, the curriculum management of the innovation seminar will dynamically adjust the teaching norms and performance evaluation of the seminar to reflect the basic characteristics and internal laws of the seminar.

\section{References}

[1] Li Y, He Q. Advantages and reference of teaching mode of the foreign research[J]. China higher education, 2009 (1) : 60-62.

[2] Huang Hui. The glance of the educational management mechanism in Yale University [J]. The journal of educational science in Hunan Normal University, 2007 (02) : 66-69.

[3] Chen Y, Liu S, Zhang Y. The empirical study of teaching reform of small class seminar in Peking University.[J]. Education monthly, 2013 (11) : 25-30.

[4] Xuan T, Huang W. Experience and analysis of freshmen seminar in college[J]. Chinese college education, 2014 (02):33-36.

[5] Lu X, Sun Y. Teaching promote development of Seminar in universities[J]. Chinese college education, 2009, (12): 65-68.

[6] Liu H. The evaluation system of development of classroom teaching index : design ideas and examples[J]. global education forecast, 2013, (3): 48-56.

[7] Chen F. the solution of construction and difficulties of freshman seminar: based on the practical exploration in Shanghai University[J]. Chinese college education, 2014 (6) : 64-67.

[8] Zhao H. The development of cultivation and scientific research consciousness of college students-practice and reflection of freshmen seminar[J].Internet education, 2014 (2) : 1-4. 